\title{
Avaliação de uma intervenção pedagógica na aprendizagem de crianças com Transtorno de Déficit de Atenção e Hiperatividade - TDAH - no âmbito das políticas públicas do Estado do Pará
}

\author{
- Ione Lima Pina* \\ 口uciel da Silva Macedo** \\ - Manuel Elbio Aquino Sequeira*** \\ 口 Iris Lima e Silva $* * * *$ \\ Fabrício Cardoso $* * * * *$ \\ - Fátima Cunha Pinto $* * * * * *$ \\ 口 Heron Beresford $* * * * * * *$
}

\section{Resumo}

As Políticas Públicas Educacionais no Estado do Pará são estabelecidas em consonância com a esfera federal por meio de Diretrizes que objetivam, fundamentalmente, contemplar seus educandos com um ensino equânime e democrático. Os alunos com carências muito especiais encontram guarida em intervenções planejadas e executadas como um valioso meio para preencher positivamente determinadas lacunas. Este artigo objetivou avaliar a eficácia de uma intervenção pedagógica voltada para a aprendizagem de crianças, entre 7 e 10 anos, com diagnóstico interdisciplinar de Transtorno de Déficit de Atenção e Hiperatividade (TDAH). Aplicou-se o Teste de Processamento Mental, o Teste de Desenvolvimento Escolar e uma Intervenção Pedagógica a partir da combinação de um programa de atividades ludomotoras, composta de jogos educacionais, com um programa de estimulação cortical. Os resultados sugeridos forneceram respostas não conservadoras e positivas, relaci-

\footnotetext{
* Mestranda em Ciência da Motricidade Humana, Universidade Castelo Branco-RJ (UCB/RJ); Professora da Secretaria Executiva de Estado de Educação do Pará (SEDUC/PA) e do Instituto Dom Bosco de Belém-PA. E-mail: ione.pina@hotmail.com

* $\quad$ Mestrando em Ciência da Motricidade Humana da UCB/RJ; Professor da SEDUC/PA e do Colégio Marista Nossa Senhora Nazaré e do Colégio Teorema de Belém-PA.E-mail: lucielmacedo@yahoo.com.br

*** Mestrando em Ciência da Motricidade Humana da UCB/RJ; Professor e Coordenador da Universidade Luterana de Santarém-PA.E-mail: profemanolo@.hotmail.com.

**** Mestre em Ciência da Motricidade Humana, UCB/RJ; Pesquisadora do Laboratório de Temas Filosóficos em Conhecimento aplicado - LABFILC/RJ. E-mail: irislimaucb@yahoo.com.br.

***** Mestre em Ciência da Motricidade Humana da UCB/RJ; Pesquisador do LABFILC/RJ. E-mail: fbc@bmrio.com.br

***** Pós-doutora UNED, Madri, Espanha; Doutora em Filosofia - Universidade Gama Filho (UGF/RJ); bolsista da CAPES; Fundação Cesgranrio.E-mail: fatimacunha@cesgranrio.org.br.

******* Doutor em Filosofia, UGF/RJ; Professor Titular do Programa de Pós-Graduação Stricto Senso em Ciência da Motricidade Humana da UCB-RJ; Professor Adjunto da Universidade do Estado do Rio de Janeiro (UERJ).

E-mail: heronberesford@gmail.com.
} 
onadas à aquisição da linguagem lectoescrita. Ademais, a intervenção, com base na ludoergomotricidade, mostrou efeito positivo e seu valor comprovado por permitir uma melhora dessas crianças em relação à dificuldade por elas expressada.

Palavras-chave: Valor. Intervenção pedagógica. Políticas Públicas. Transtorno do Déficit de Atenção e Hiperatividade.

\section{Evaluation of a pedagogic intervention in the learning process of children with Attention Deficit and Hyperactivity Disorder and the public policies in Pará state Abstract}

The Educational Policies in Pará State are established according the Federal Power through statements with the objective of attend their students with a democratic process of learning. The students with special necessities find protection inside the planned interventions that were executed as valorous mean to fulfill in the positive way some necessities. This paper had the aim to evaluate the efficiency of a pedagogic intervention toward the learning process of children that are 7 to 10 years old and were diagnosed with attention deficit and hyperactivity mental disorder (ADHD). Was applied a Mental Process Test a Scholar Development Test and a pedagogic intervention starting from a combination of motor-play skill activities composed by educational games, and a cortical stimulation program. Suggested results gave non conservatives and positive responses related to the acquiring of writing and reading process. Also, the intervention based on motorplay skills, showed a positive effect and proved its value because allowed an improvement of those children related to the difficulty expressed by themselves. Keywords: Value. Pedagogic intervention. Public Policies. Attention Déficit and Hyperactivity Mental Disorder.

\section{Evaluación de una intervención pedagógica en la enseñanza de niños com Trastorno de Déficit de Atención y Hiperactividad - TDAH - y en el ámbito de las Politicas Públicas del estado de Pará Resumen}

Las Politicas Públicas de Educación en el Estado de Pará, Brasil, son establecidas en consonancia con la esfera Federal por medio de Directrices que objetivan fundamentalmente, contemplar sus educandos con una enseñanza ecuánime y democrática. Los alumnos con necesidades muy especiales encuentran refugio en 
intervenciones planeadas y ejecutadas como un valioso medio para llenar positivamente determinadas lagunas. Este artículo tuvo el objetivo de evaluar la eficacia de una intervención pedagógica destinada a la enseñanza de niños entre 7 y 10 años, diagnosticados con Trastorno de Déficit de Atención y Hiperactividad.(TDAH). Fue aplicado el Teste de Procesamiento Mental, el Teste de Desarrollo Escolar, y una Intervención Pedagógica a partir de la combinación de un programa de actividades ludo motoras, compuesta de juegos educacionales, con un programa de estimulación cortical. Los resultados, sugieren respuestas no conservadoras y positivas relacionadas a la adquisición del lenguaje escrito y de lectura. Además, la intervención, con base en la ludoergomotricidade, mostró efecto positivo y su valor comprobado por permitir una mejora de esos niños con relación a la dificultad por ellos expresada.

Palabras clave: Valor. Intervención pedagógica. Políticas Públicas. Trastorno de Déficit de Atención y Hiperactividad.

\section{Introdução}

0 Estado do Pará promove as diretrizes para alcançar a qualidade da educação pública em consonância com as esferas federal, estadual e municipal em objetivos, metas e ações sociais com vistas à equidade e democratização do ensino público "Pará Todos" (PARÁ, 2008).

Identifica-se claramente, no Estado do Pará, um estilo de desenvolvimento diferenciado e ousado, pois, pela maneira como assume esta responsabilidade, o sistema educacional tende a experienciar uma expansão qualitativa e quantitativa de acordo com o proposto no Plano Plurianual (PPA) para o quadriênio 2008-2011 (PARÁ, 2007), no qual as concepções imperantes sobre o desenvolvimento educacional são: a democratização, como ponto central de orientação política, e o avanço em busca de uma educação de qualidade e equidade.

Um dos aspectos desafiadores que requerem atenção governamental diz respeito à educação e inclusão de alunos com necessidades especiais, a exemplo dos alunos com Transtorno de Déficit de Atenção e Hiperatividade (TDAH), no contexto escolar e extraescolar. A Secretaria Executiva de Estado de Educação do Pará (SEDUC/PA), diante dos compromissos assumidos pelo Governo Popular, dentre eles o respeito à diversidade, traça as diretrizes de uma política pública inclusiva na perspectiva da construção e afirmação de identidades [...] que devem transcender ao espaço escolar [...] (PARÁ, 2008).

Assim, os programas (diretrizes), ações, objetivos e metas que constituem as bases da atual política educacional em âmbito nacional se têm desenvolvido de forma articulada entre as esferas do poder federal, estadual e municipal, o que faz com que as ações se completem e se potencializem nos estabelecimentos de ensino público, visando à promoção do bem - estar social. 
0 PPA do Estado do Pará, para o quadriênio 2008-2011 (PARÁ, 2007), busca respostas para questões fundamentais, como: - Quais são as ações para reduzir as desigualdades entre as regiões de integração (no caso do Estado do Pará - PPA Territorial e Participativo)?; - Quais são os projetos finalísticos que receberão recursos para infraestrutura, bem como recursos de custeio e pagamento de pessoal (Servidores e Defensores)?; - Quais serão os Projetos que receberão aporte de recursos provenientes de Convênios com outros entes da Federação?.

Desta feita enfatiza-se a importância do papel dos órgãos institucionalizados para que a Política de Educação Básica se efetive com qualidade e equidade, como a proposta:

a) Na Lei $n^{\circ}$ 9.394,(BRASIL, 1996), que estabelece as Diretrizes e Bases para a Educação Nacional, no Art. 20: "A educação, dever da família e do Estado, inspirada nos principios de liberdade e nos ideais de solidariedade humana, tem por finalidade o pleno desenvolvimento do educando, seu preparo para o exercício da cidadania e sua qualificação para o trabalho" e no Art. 58 "Entende-se por educação especial, para os efeitos desta Lei, a modalidade de educação escolar, oferecida preferencialmente na rede regular de ensino, para educandos portadores de necessidades especiais";

b) Nos Parâmetros Curriculares Nacionais (BRASIL, 1997) objetiva-se desenvolver ao longo dos quatro primeiros anos do Ensino Fundamental, as habilidades de falar e escutar, ler e escrever, ou seja, o desenvolvimento da linguagem oral e da linguagem escrita;

c) De acordo com a Constituição Federal de 1988 (BRASIL, 1988), o Poder Executivo Estadual, durante o primeiro ano da administração deve dar continuidade ao desenvolvimento dos programas e ações do PPA existente e elaborar um novo PPA, que vai vigorar durante os três anos restantes da sua gestão e o primeiro ano da administração que lhe suceder.

A SEDUC/PA (PARÁ, 2008, p. 9) concebe a intenção da política pública para o Estado como inclusiva e democrática, pois:

A edificação de uma nova práxis pedagógica materializada e os anseios dos sujeitos comprometidos com o ensino público estadual, definindo os novos rumos de nosso Estado, sob a perspectiva de um projeto educacional democrático e de qualidade Pará Todos. 
A SEDUC/PA visando ainda ao reconhecimento e à legitimação da diversidade que nos dizeres de Maués $(2008$, p. 121) é plenamente reforçado:

A definição de políticas públicas que incorporem questões
ligadas à inclusão e à diversidade, [...], deverá encarar do
ponto de vista epistemológico, político e operacional a
complexidade das questões ligadas à cultura e à diferença
no contexto de uma prática social - educacional -, que lida
com exigências de universalização e universalidade.

Por outro lado, todas as Leis norteadoras, os Planos e os Programas de financiamento e diretrizes do fazer educativo traçadas para o desenvolvimento da educação no Estado ainda são insuficientes, muito embora venham apresentando um grande avanço, pois a discussão sobre a inclusão e diversidade (PARÁ, 2008) vem se fazendo presente por meio da construção dos princípios - de inclusão e diversidade cultural - para uma educação democrática.

Nesse contexto, acerca da Política Pública da Educação para o Estado do Pará, pode-se considerar a aprendizagem, como um "processo de atividade pessoal, reflexiva e sistemática, dependente do acionamento de todas as potencialidades do educando [...] que acontece quando se satisfaz os motivos individuais, que impulsionam à atividade necessária para aprender" (CAMPOS, 2007). As crianças com o TDAH apresentam dificuldade em integrar os mecanismos neurais responsáveis pelo funcionamento do Sistema Nervoso Central (SNC), afetando assim a capacidade de captarem um estimulo, o que a médio e a longo prazo afeta, particularmente, a aquisição de conteúdos (RELVAS, 2007).

Nesse contexto, a aprendizagem, segundo Bessa (2006), envolve quatro elementos, que são:

a) Memória: na maioria dos casos tratada como a capacidade de armazenamento de informações no cérebro, ou ainda como a capacidade de resgatar aquilo que foi armazenado;

b) Atenção: constitui-se em um processo de concentração, podendo-se afirmar que a concentração ocorre a partir de estímulos, que tanto podem ser internos como externos;

c) Interesse: Pode-se definir como a relação estabelecida entre o sujeito e o objeto, na qual o primeiro sente-se atraído pelo segundo por meio de algum estímulo produzido pelo segundo em relação ao primeiro, e

d) Inteligência: Costuma-se aferir ao conceito de inteligência, a capacidade de uma pessoa compreender facilmente as informações que lhes são transmitidas, sendo assim, chama-se inteligente aquele que possui facilidade de aprender. 
Assim, o ato de aprender engendra em sua dinâmica a atenção, a memória, o interesse e a inteligência, tornando-se uma ação complexa que pode ou não determinar a apreensão de fatos, conceitos, nomes, conteúdos do currículo escolar e principalmente a decodificação de códigos linguisticos - leitura ou aquisição da representação gráfica - escrita.

A atenção para Atkinson e outros (2002) é a capacidade de selecionar algumas informações para exame mais detalhado e ignorar outras, e é importante para que um estímulo seja percebido, posteriormente elaborado e transformado em resposta, que, em seguida, é analisada.

Nessas condições, o processo atencional é imprescindível à efetivação da aprendizagem. É por esse motivo que Kolb e Whishaw (1996) propuseram uma interessante classificação acerca dos mecanismos psíquicos, necessários a este processo, a saber:

- atenção concentrada mediante a qual o sujeito detém-se em determinado estímulo e tenta compreendê-lo;

- atenção sustentada à medida que mantém a concentração, a atividade mental seleciona o estímulo e o processo atencional é dirigido para ele e mantido até que se consiga a finalização da tarefa pretendida, e

- atenção seletiva como capacidade de processar determinadas informações e estímulos que chegam ao cérebro, principalmente por meio dos órgãos sensoriais, onde o indivíduo direciona, mantém ou modifica o foco da consciência para a fonte estimuladora provedora das informações e, assim, mantém o direcionamento mental para a mesma, até a conclusão da tarefa cognitiva proposta.

Bears, Connors e Paradiso (2002, p. 659) demonstraram que a "atenção aumenta a velocidade de reação a estímulos visuais".

Em continuidade ao assunto, Dulcan e Benson (1997, p. 1311-1317) comentam hipoteticamente:

[...] Sendo provável que a atenção se volte para um objeto ou fato de interferência antes que seus olhos se movam. 0 estado atentivo contribui decisivamente para as alterações que se operam na organização cognitiva e que, em última instância, são responsáveis pela aprendizagem e pela memorização do conteúdo aprendido, ou seja, pelos processos mentais.

0 controle dos mecanismos mentais é aprendido pela criança e aperfeiçoado durante todo o processo de escolaridade, este representa a "capacidade de a criança "pensar sobre o pensamento", avaliar uma tarefa cognitiva, para decidir a melhor maneira de cumpri-la" e as estratégias de armazenagem e de recuperação das informações melhorarem, Berger (2001). 
Ainda para os autores, a capacidade cerebral de potencializar mudanças e aprendizagens, de forma constante e ininterrupta, a qual alguns pesquisadores denominam de plasticidade cerebral, se refere ao fato de que as aptidões cognitivas podem ser moldadas por muitos fatores, principalmente pela instrução e o treinamento [...]. A quantidade de informação que pode ser colocada em um mesmo cérebro é praticamente ilimitada (BERGER, 2001, p. 379).

Assim, pode-se dizer que a atenção representa a condição inicial e decisiva para as funções cognitivas em sua totalidade, particularmente para o processo de aprendizagem e de memorização.

Izquierdo (2002) emprega o termo memória para designar a capacidade geral do cérebro e dos demais sistemas em adquirir, guardar e lembrar informações. Para ele, 0 termo "memórias" é utilizado para designar cada tipo delas, segundo sua função, a saber:

- memória de trabalho: gerencia a realidade e determina o contexto em que os diversos fatos, acontecimentos ou outro tipo de informação ocorrem, e se vale a pena ou não fazer uma nova memória disto, ou se esse tipo de informação já consta dos arquivos. Diferencia-se das demais por não deixar traços e não produzir arquivos;

- memória de curta duração: estende-se desde os primeiros segundos ou minutos seguintes ao aprendizado, depende do prévio processamento das informações pela memória de trabalho, é seletivamente afetada por muitos estímulos administrados nas mesmas áreas que processam a memória de longa duração e o conteúdo é basicamente o mesmo da memória de longa duração, e

- memória de longa duração ou declarativa: diz respeito ao processo que leva à fixação definitiva das informações, e a maneira em que mais tarde poderão ser evocadas denomina-se consolidação. Este tipo de memória depende do prévio processamento das informações pela memória de trabalho.

As crianças com diagnóstico de TDAH precisam de ajuda para superar alguns fatores como: uma percepção confusa sobre o mundo social; o desprezo que sentem sobre si mesmas; um déficit de atenção e aumentar a capacidade de memória. Isto porque tais fatores podem ser decisivos como geradores de consequências desagradáveis ao processo de aprendizagem escolar (BERGER, 2001, p. 208).

Com relação ao processo de aquisição da linguagem lectoescrita, vale ressaltar que a criança com TDAH apresenta, em seu desenvolvimento escolar, carências múltiplas expressas corporalmente, por meio da dificuldade de concentração; de seguirem regras estabelecidas; de controle dos impulsos; de se organizarem e da tendência ao adiamento ou abandono de tarefas que Ihes exijam atenção concentrada, bem como das relacionadas ao déficit de transferência e retenção de atenção da memória operacional para a memória de longa duração (BARKLEY, 2002). 
Dessa maneira, para Goldstein e Goldstein (2006), essas crianças TDAH são comumente caracterizadas por avaliações pedagógicas isoladas e equivocadas, como incapazes, imaturas e inaptas, colaborando, assim, segundo outros estudiosos do desenvolvimento humano, para a instalação de um comportamento infantil limitado, gerador de dificuldades de natureza biofísica, bissocial, biomoral e biopsíquica, o que muito provavelmente poderá acarretar como consequência, o fracasso dessas crianças TDAH, não só na escola, como também em outros aspectos que envolvem a vida das mesmas (PAPALIA; OLDS, 2000; RAZERA, 2001; BENCZIC, 2002; BERGER, 2004; GOLDSTEIN; GOLDSTEIN, 2006; CAMPOS, 2007; THOMPSON, 2007; MALUF, 2007; ARRUDA, 2007).

Nas séries iniciais do Ensino Fundamental, as crianças TDAH, comumente, são acometidas de uma presente dificuldade em efetivar sua aprendizagem, principalmente a relacionada às habilidades que envolvem a aquisição da lectoescrita (TOPCZWSKI, 1999, p. 56).

Ao longo do período de escolaridade, as dificuldades apresentadas ou mesmo impostas a essas crianças, em relação à aquisição da leitura e escrita representam, sobremaneira, um desafio a ser refutado por profissionais e familiares com que convivem e que as orientam, pois há algum tempo, por meio das políticas públicas nacionais implementadas verifica-se uma proposta recorrente de se romper com visões deterministas que negam o direito de acesso e de efetivação da aprendizagem, incentivando, textualmente, estudos multidisciplinares seguidos de intervenções que efetivamente corroboram para suprir as carências expressas corporalmente por essas crianças TDAH.

Levando-se em consideração o que foi descrito anteriormente, este estudo teve por objetivo avaliar a eficácia de uma intervenção pedagógica voltada para atuar no déficit de transferência de atenção da memória operacional para a memória de longa duração. Isso com o propósito de reduzir a dificuldade de vida existencial que crianças com TDAH de ambos os sexos, com idades compreendidas entre 7 e 10 anos, atendidas na Unidade Técnica de Educação Especial (UTEES), no Distrito de Icoaracy (Belém/PA), expressam, corporalmente, para manter uma capacidade de concentração indispensável à aquisição da linguagem lectoescrita.

\section{Ética da pesquisa}

0 projeto desta pesquisa foi submetido ao Comitê de Ética em Pesquisa envolvendo Seres Humanos da Universidade Castelo Branco (UCB/RJ) e aprovado sob protocolo n 0172"2008.

A coleta de dados se deu conforme a Resolução 196/96 (CONSELHO NACIONAL DE SAÚdE, 1996). 
Assim, inicialmente foi solicitada autorização dos pais ou responsáveis para que o estudo fosse desenvolvido, por meio de um Termo de Consentimento Livre e Esclarecido ao qual se anexou uma carta de esclarecimentos, explicando-se a natureza do estudo.

\section{Metodologia}

\section{Tipologia do estudo}

0 presente estudo foi desenvolvido por meio do formato ou desenho experimental, considerando-se que uma pesquisa experimental consiste em determinar um objeto de estudo, selecionar as variáveis que seriam capazes de influenciá-lo, definir as formas de controle e de observação dos efeitos que a variável independente produz diretamente na variável dependente, isto sendo realizado em uma avaliação antes (pré-teste), e outra avaliação após (pós-teste) a aplicação da intervenção (BARROS; LEFEHELD, 2000).

\section{Grupo avaliado}

Os participantes do estudo pertencem a um grupo denominado voluntário por Cochran (1956), correspondente a 10 alunos com TDAH, na faixa etária de 07 a 10 anos, matriculados na rede pública estadual de ensino, de $1^{\text {a }}$ a $4^{\text {a }}$ séries do ensino fundamental, atendidos em salas de recurso da Unidade Técnica de Ensino Especializado (UTES), no Distrito de Icoaracy (Belém/PA).

\section{Procedimentos de avaliação}

Foi utilizado em nosso estudo, como instrumento de avaliação, o Teste de Processamento Mental (TPM), proposto por Silva (2004) e o Teste de Desempenho Escolar (TDE), proposto por Stein (1994).

Cada teste foi aplicado no instante antes (pré-teste), e no instante depois da intervenção pedagógica (pós-teste).

Teste de Processamento Mental (TPM): tem por objetivo avaliar "o tempo que decorre da apresentação de um estimulo não antecipado ao início da resposta". De acordo com Schmidt e Wrisberg, (2001), o tempo de reação aumenta a medida da lei de Hick e o TPM foi medido por intemédio do teste de dupla escolha, elaborado no modelo informatizado por Silva (2004), com as seguintes características:

- aparecem três quadrados na tela. um quadrado está posicionado no centro superior da tela para acender como luz de alerta, e outros dois, localizados cada um num canto inferior da tela para funcionarem como luz de estímulo na direita ou na esquerda de forma aleatória;

- o tempo de alerta será de 3 a 4 segundos e para o início do estímulo também em 3 a 4 segundos; 
- foi medido o tempo de resposta paralelo ao estímulo - luz do lado direito, tecla do lado esquerdo, luz do lado esquerdo, tecla de resposta do lado direito, ou seja, a resposta de forma cruzada.

Teste de Desempenho Escolar (TDE): instrumento psicométrico que busca avaliar, de forma objetiva, o desempenho escolar, mais especificamente da escrita, aritmética e leitura, de alunos de $1^{\text {a }}$ a $6^{\text {a }}$ séries do Ensino Fundamental. Ele é composto por três subtestes (STEIN, 1994). Neste estudo foram utilizados somente os subtestes relacionados à escrita e à leitura, que consistiu em:

- um ditado de 45 palavras, em Língua Portuguesa, de nomes próprios, isoladas em ordem crescente de dificuldade ortográfica e adequadas a alunos de $1^{\text {a }}$ a $4^{\text {a }}$ séries do Ensino Fundamental, e

- reconhecer, em uma escala de 75 palavras de Língua Portuguesa, palavras isoladas do contexto, levando em consideração a gradação dos fonemas, número de sílabas, grau de familiaridade do vocábulo e padrões silábicos.

0 Escore Bruto (EB) de cada subteste e o Escore Bruto Total (EBT) de todo o Teste de Desenvolvimento Escolar (TDE) foram convertidos em uma média final.

\section{Procedimento de intervenção}

As crianças participantes deste estudo realizaram os testes propostos na Unidade Técnica de Educação Especial (UTEES) de Icoaracy (Belém/PA), em sala adequadamente preparadas com cadeiras e mesas individuais em sala arejada, silenciosa e com iluminação natural, bem como se assegurou uma infraestrutura com os recursos tecnológicos e lúdicos necessários.

A intervenção neuropedagógica foi realizada a partir da combinação de um programa de atividades lúdicas com um programa de potencialização cerebral, composta por batidas binaural, durante 20 sessões, com duração de 35 minutos.

0 Programa de Atividades Lúdicas foi executado pelas crianças sob a orientação dos pesquisadores que, após explicação das tarefas, deu início a realização das mesmas, onde cada criança escolheu livremente e manuseou observando as regras dos jogos verificados abaixo, com objetivos específicos e definidos.

No "Jogo dos Absurdos" buscou-se desenvolver na criança a percepção e a interpretação através de uma dada realidade de uma história comparada a desenhos.

Por meio do "Jogo dos Erros" requereu-se o uso da atenção concentrada nas tarefas de encontrar semelhanças e diferenças por meio da comparação entre objetos. 
No "Jogo Onde Está?" propõe-se estimular a percepção analítica através da divisão do todo em partes, desenvolvendo pensamento divergente e estimular e mediar a integração das partes em um todo, desenvolvendo o pensamento convergente.

Já no manuseio do "Jogo Dominó das Palavras" apresentaram-se situações desafios e de estimulo à competição, à cooperação e ao respeito dos seus próprios limites e ao do outro, bem como o cumprimento e respeito às regras estabelecidas.

No Programa de Aplicação da Potencialização Cerebral cada criança participante recebeu um aparelho de CD Player da marca Brithânia, com fone de ouvidos estéreos. A metodologia protocolar baseou-se em frequências de alfa, entre 8 e 13 $\mathrm{Hz}$, conforme normalmente é utilizada em estudos nesta linha de investigação que, para Siever (1999) e Cardoso (2007), corresponde à estimulação correta para a aprendizagem adequada à frequência como alfa, delta ou teta que faz com que o córtex o acompanhe.

\section{Apresentação e análise dos resultados}

Num primeiro momento as informações obtidas (resultantes dos Testes de Processamento Mental e o de Desempenho Escolar), foram analisadas de acordo com os resultados expressos por meio dos dados estatísticos distribuídos na Tabela 1, a seguir apresentada.

Tabela 1: Resultados das avaliações (pré-testes) por criança.

\begin{tabular}{c|c|c|c}
\hline Nome & Idade & TPM (segundos) & TDE (acertos) \\
\hline Bacaba & 09 anos & 5,876 & 13 \\
\hline Cupuaçu & 10 anos & 11,72 & 22 \\
\hline Açai & 10 anos & 12,824 & 5,5 \\
\hline Bacuri & 10 anos & 9,209 & 1,5 \\
\hline Taperebá & 10 anos & 4,518 & 25,5 \\
\hline Pupunha & 09 anos & 3,413 & 9,5 \\
\hline Castanha & 10 anos & 3,258 & 21,5 \\
\hline Tucumã & 08 anos & 4,839 & 1 \\
\hline Biribá & 10 anos & 4,273333 & 12 \\
\hline Graviola & 08 anos & 6,238 & 11,25 \\
\hline MÉDIA & & 6,616833 &
\end{tabular}

Fonte: Protocolo de Pesquisa (2008).

A primeira etapa da avaliação ( $A v 1)$ permitiu se discriminar-se o estágio em que as crianças se encontravam em relação à aquisição da lectoescrita, assim como avaliar a relação entre o estado de atenção e a linguagem lectoescrita de crianças com TDAH. 
Os resultados obtidos foram processados de acordo com a estatística descritiva, recorrendo às medidas de tendência central (média e mediana), separatrizes (P25 e P75) e as medidas de dispersão de dados (Mínimo, Máximo, Amplitude e DesvioPadrão), conforme as tabelas apresentadas a seguir nas Tabelas 2,3 e 4:

Tabela 2: Resumo Descritivo referente aos testes (TPM, TDE).

\begin{tabular}{c|c|c|c|c|c|c}
\hline Variáveis & Mínimo & Máximo & Mediana & (P25-P75) & Média & Desvio padrão \\
\hline TPM & 3.258 & 12.824 & 5.358 & $(4.334-8.466$ & 6.617 & \pm 3.441 \\
\hline TDE & 1 & 25.5 & 10.75 & $(2.5-19.38)$ & 11.2 & \pm 9.24 \\
\hline
\end{tabular}

Fonte: Protocolo de Pesquisa (2008).

Por meio dos dados obtidos na Tabela 2 permite-se dizer que o Tempo de Processamento Mental (TPM), ou seja, a resposta a um estímulo não antecipado, o escore mínimo observado foi de 3.258 segundos, e o máximo, de12.824 segundos.

A partir do que foi comentado no parágrafo anterior, pode-se ressaltar que:

- 75\% das crianças têm o TPM abaixo de 8.466 segundos; 25\% das crianças têm um TPM abaixo de 4.334 segundos, e que 50\% das crianças apresentaram o TPM abaixo de 5.358 .

Com relação ao Teste de Desempenho Escolar (TDE), pode ser dito que:

- o valor mínimo obtido foi de 1 (uma) palavra, e o máximo, de 25.5 palavras;

- 75\% das crianças acertaram abaixo de 19.38 palavras;

- 25\% das crianças acertaram abaixo 2.5 palavras;

- 50\% das crianças acertaram abaixo de 10.75 palavras, e

- o valor médio de acertos foi igual a $11.25 \pm 9.24$ palavras.

Por meio da análise dos dois testes aplicados pode-se dizer que os problemas das crianças com TDAH residem nas áreas de percepção, atenção, memória, associação e fixação de informações. Não se está falando de uma lesão ou defeito e sim de um funcionamento diferente do cérebro.

Isto ocorre, porque uma pessoa que tem TDAH, segundo Barkley (2002), apresenta um menor fluxo sanguíneo na região frontal do cérebro, responsável pelo comportamento inibitório (freio), o que influencia na capacidade de planejamento, memória seletiva, regula o estado de vigília, filtra os estímulos, entre outras funções. Principalmente as que são responsáveis pela Área verbal: problemas na codificação/ decodificação simbólica, irregularidades na lectoescrita (GIRON; MACEDO, 2008). 
Ao se fazer uma análise mais específica acerca do teste TDE, que envolve o desempenho em leitura e escrita, pode-se dizer que a maioria das crianças avaliadas encontra-se no estágio silábico alfabético para o nível alfabético para silábico. Somente as crianças Cupuaçu, Taperebá e Castanha encontram-se firmemente no estágio alfabético.

Ao se analisar o Teste de Processamento Mental, pode-se dizer que os resultados obtidos estão em conformidade com a proposição de Motter (1993, p. 909-919), ou seja, que:

A descarga neuronal excessiva afeta todo o processo para se cumprir uma tarefa que exige um grau complexo de concentração e memorização em curto prazo, pois afeta a atividade de áreas do cérebro que processam as caracteristicas dos estímulos, como cor, movimento, textura e forma.

Aplicados os Testes comentados, após 20 sessões, associou-se aos mesmos uma intervenção pedagógica, durante quarenta sessões, com base em atividades lúdicas e em um Programa de Aplicação da Potencialização Cerebral, a qual permitiu avaliar a eficácia da referida intervenção pedagógica, obtendo-se a análise:

Tabela 3: Resumo Descritivo do Teste de Processamento Mental (TPM).

\begin{tabular}{|c|c|c|}
\hline & 1 a Avaliação (AV 1) & 2a Avaliação (AV 2) \\
\hline Tempo Mínimo de reação & 3 & 1 \\
\hline Tempo Máximo de reação & 12 & 3 \\
\hline Amplitude Total & 9 & 2 \\
\hline Mediana & 4.5 & 2 \\
\hline Primeiro Quartil (25\%) & 4 & 2 \\
\hline Terceiro Quartil (75\%) & 8.25 & 3 \\
\hline Desvio Interquartilico & 4.25 & 1 \\
\hline Média Aritimética & 6.1 & 2.2 \\
\hline Variância & 11.2111 & 0.6222 \\
\hline Desvio Padrão & 3.3483 & 0.7888 \\
\hline Erro Padrão & 1.0588 & 0.2494 \\
\hline Coeficiente de variação & $54.89 \%$ & $35.86 \%$ \\
\hline
\end{tabular}

Fonte: Protocolo de Pesquisa (2008).

Nota: $p$-valor $=0.0051^{*}$, Teste de Wilcoxon para amostras pareadas. 
Tabela 4: Resumo Descritivo do Teste de Desempenho Escolar (TDE).

\begin{tabular}{c|c|c}
\hline & 1 ${ }^{\text {a }}$ Avaliação (AV 1) & 2 $^{\text {a }}$ Avaliação (AV 2) \\
\hline Mínimo de acertos & 1 & 3 \\
\hline Máximo de acertos & 25 & 33 \\
\hline Amplitude Total & 24 & 30 \\
\hline Mediana & 10.5 & 29 \\
\hline Primeiro Quartil (25\%) & 2 & 17 \\
\hline Terceiro Quartil (75\%) & 19 & 31 \\
\hline Desvio Interquartilico & 17 & 14 \\
\hline Média Aritimética & 11 & 22.4 \\
\hline Variância & 84.6667 & 137.1556 \\
\hline Desvio Padrão & 9.2014 & 3.7113 \\
\hline Erro Padrão & 2.9098 & 3.7035 \\
\hline Coeficiente de variação & $83.65 \%$ & $52.28 \%$ \\
\hline
\end{tabular}

Fonte: Protocolo de Pesquisa (2008).

Nota: $p$-valor $=0.0125^{*}$, Teste de Wilcoxon para amostras pareadas.

Os dados apresentados na Tabela 3, relativos ao Teste de Processamento Mental (TPM), representam o tempo mínimo e o máximo decorridos da apresentação de um estímulo não antecipado em relação ao início das respostas das crianças avaliadas na primeira e na segunda avaliação.

Relativamente à AV 1, verificou-se que o tempo mínimo decorrido da apresentação de um estímulo não antecipado ao início da resposta das crianças com TDAH foi de 3.258 segundos, e o máximo, de 12.824 segundos. Configurando-se ainda nessa primeira avaliação que $75 \%$ das crianças mostraram resposta através de um tempo abaixo de 8.466 segundos; já $25 \%$ dos alunos, abaixo de 4.334 segundos; e $50 \%$, abaixo de 5.358 .

Correlacionando-se os resultados obtidos na Tabela 3, referente às avaliações 1 e 2 , pode-se verificar que houve significativa alteração do tempo de resposta das crianças ao estímulo não antecipado de, no mínimo, 1 segundo, e no máximo, de 3 segundos.

Reforçando-se esse resultado em termos percentuais, verificou-se que 75\% dos alunos demonstraram reação em tempo de 3 segundos; 50\%, em 2 segundos, e 25\%, em tempo de 1 segundo.

0 nivel de significância dos resultados obtidos após a intervenção foi realizada pelo teste de Wilcoxon (Signed Rank test), conforme prescrito por Ayres e outros (2008) para amostras pareadas, tendo-se obtido um $p=0.0051$, indicando que houve significativa melhora no desempenho demonstrado na segunda avaliação. 
Pode-se observar que o tempo de reação ao estímulo apresentado pelas crianças diminuiu, o que está de acordo com os autores que embasam o referido Teste, pois a intenção é de responder ao estímulo no menor tempo possível.

Os dados encontrados na Tabela 4, relativos ao TDE, representam o desempenho das crianças avaliadas em relação aos acertos na escrita e na leitura de palavras apresentados na primeira e na segunda avaliações.

$\mathrm{Na}$ AV 1 o mínimo de acertos foi de uma palavra, e o máximo, de vinte e cinco palavras e meia. Evidenciando-se que 75\% das crianças acertaram menos de 19,38 palavras, 50\% acertaram menos de 10.75 palavras e 25\% acertaram menos de 2,5\% palavras. o valor médio de acertos foi de 11,25 palavras.

Em contrapartida, através da AV 2 mostrou-se que o mínimo de acertos foi de três palavras, e o máximo, de 33. Em termos percentuais, os números representam que $75 \%$ das crianças acertaram menos de 31 palavras, 25\%, menos de 17, e 50\%, menos de 29. 0 valor médio dos acertos foi de 22.40 palavras.

0 nivel de significância das diferenças entre os resultados obtidos nas avaliações 1 e 2 para o TDE foi realizada pelo teste de Wilcoxon para amostras pareadas, obtendose um $p=0.0121^{*}$, o que indica que houve significativa melhora no desempenho das crianças após a intervenção realizada, na escrita e leitura das palavras propostas.

Assim pode-se dizer que estes resultados vêm somente confirmar os estudos de Cardoso (2007), Silva (2006), Rabello (2007), de que o cérebro é uma estrutura altamente plástica e que, por meio de estímulo externo auditivo, é possível promover um balanceamento cerebral que processe o equilíbrio do cérebro em suas diversas áreas e funções. A atividade elétrica gerada pelos neurônios se dá de forma proporcional, coerente e adequada, traduzindo-se em harmonia e equilibrio psicofísico que pode otimizar a aprendizagem e a memorização.

Portanto, a intervenção pedagógica, composta pela estimulação cortical, sendo aplicada simultaneamente com atividades ludomotoras, promoveu uma adaptação dos mecanismos neurais do córtex responsável pela conexão intrahemisférica, com isso melhorando o déficit de transferência de atenção da memória operacional para a memória de longa duração, preenchendo assim, positivamente, a carência ou a dificuldade que crianças com TDAH apresentavam na aquisição da linguagem lectoescrita. Desta forma, ficou comprovado o valor agregado de tal intervenção pedagógica.

Isso porque entende-se por valor uma qualidade estrutural de natureza metafisica que corresponde a tudo aquilo (no caso, à referida intervenção pedagógica) que preenche positivamente um complexo estado de carência, privação ou de vacuidade 
(no caso, melhorando o déficit de transferência de atenção da memória operacional, o déficit de atenção ou de concentração prolongado) de um ente do Ser do Homem (no caso, crianças com TDAH) (BERESFORD, 2008).

\section{Conclusão}

Após realização e análise dos resultados da pesquisa foi possivel verificar que a implementação de programas de intervenção multidisciplinar, com ênfase na ludoergomotricidade, torna-se necessária ao desvelamento de possiveis caminhos para a aquisição da linguagem lectoescrita, como ação democratizadora do processo de escolarização de crianças com TDAH.

Nessas condições, foi oferecido a tais crianças um ambiente suficientemente rico em estímulos, capaz de deixá-las agir por si mesmas, sem lhes impor ou mesmo propor quadros de soluções já prontas, devendo o professor, fundamentalmente, conhecer primeiro o perfil cognitivo de seus alunos para depois planejar, executar e avaliar as atividades pedagógicas de acordo com o perfil referido.

A par disso, pode-se concluir que as crianças com TDAH, caracterizadas com objeto formal deste estudo, foram beneficiadas após a intervenção pedagógica efetivada, pois se pôde constatar que houve condições e respostas positivas ao estimulo educacional proposto. Portanto, ocorreria comprovadamente uma valiosa melhora em termos de eficácia na aquisição da leitura e escrita e, conseqüentemente, um impacto positivo ou de relevante ganho na estrutura de aprendizagem das crianças avaliadas a ponto de propiciar-lhes condições muito favoráveis de acesso a outros patamares do desenvolvimento humano.

\section{Referências}

ARRUDA, M. A. Transtorno do Déficit de Atenção e Hiperatividade: abordagem sinóptica para o não-especialista. In: VALLE, L. E. L. R. et al. (Org.). Mente e corpo: integração multidisciplinar em neuropsicologia. Rio de Janeiro: Wasak, 2007.

ATKINSON, R. L. et al. Introdução à psicologia de Hilgard. Porto Alegre, RS: Ed. Artmed, 2002.

AYRES, M. et al. BioEstat 5: aplicações estatísticas nas áreas das ciências biológicas e médicas. 5. ed. Belém, PA: Publicações Avulsas do Mamirauá, 2008.

BARKLEY, R. A. Transtorno de déficit de atenção"hiperatividade (TDAH). Porto Alegre: Artmed, 2002.

BARROS, A. J. S.; LEHFELD, N. A. S. Fundamentos de metodologia cientifica: um guia para a iniciação científica. 2. ed. São Paulo : Makron Books, 2000. 
BEAR, M. F.; CONNORS, B. W.; PARADISO, M. A. Neurociências: desvendando o sistema nervoso. Porto Alegre: Artes Médicas, 2002.

BENCZIK, E. B. P. Transtorno de déficit de atenção/hiperatividade. Porto Alegre: Artmed, 2002.

BERESFORD, H. Valor: saiba o que é. 2. ed. Rio de Janeiro: Shape, 2008.

BERGER, K. S. O desenvolvimento da pessoa: da infância à terceira idade. Tradução de Dalton Conde de Alencar. 5. ed. Rio de Janeiro: LTC, 2001.

. 0 desenvolvimento da pessoa: do nascimento à terceira idade. 5. ed. Rio de Janeiro: LTC, 2004.

BESSA, V. H. Teorias da aprendizagem. Curitiba: IESDE, 2006.

BRASIL. Constituição (1988). Constituição Federal de 1988. Brasília, DF: CEGRAF, 1988.

Lei $n^{\circ}$. 9.394, de 20 de dezembro de 1996. Estabelece as diretrizes e bases da educação nacional. Diário Oficial [da República Federativa do Brasil], Brasilia, DF, 23 dez. 1996.

. Ministério da Educação e do Desporto. Secretaria de Educação Fundamental. Parâmetros Curriculares Nacionais: terceiro e quarto ciclos do ensino fundamental: introdução aos parâmetros curriculares nacionais. Brasília, DF, 1998.

CAMPOS, R. De perto somos todos horriveis (Tributo a J. P. Sartre). In: VALLE, L. E. L. R. et al. (Org.). Mente e corpo: integração multidisciplinar em neuropsicologia. Rio de Janeiro: Wasak, 2007.

CARDOSO, F. B. A utilização do programa de potencialização cerebral para a melhoria no lançamento da bola de boliche para atletas da seleção juvenil colombiana B. 2007. Dissertação (Mestrado em Ciência da Motricidade Humana) Programa de Pós-Graduação, Universidade Castelo Branco, Rio de Janeiro, 2007.

COCHRAN, W. G. Técnicas de amostragem. Rio de Janeiro: Aliança para o Progresso, 1956.

CONSELHO NACIONAL DE SAÚDE (Brasil). Resolução CNS 196/96, de 10 de outubro de 1996. Aprova as diretrizes e normas regulamentadoras de pesquisas envolvendo seres humanos. Diário Oficial da União, Brasilia, DF, 16 out. 1996. 
DULCAN, M. K.; BENSON, R. S. Summary of the practice parameters for the assessment and treatment of children, adolescents, and adults with ADHD. Journal of the American Academic Children and Adolescents Psychiatry, London, v. 36, n. 9, p. 1311-1317. 1997.

GIRON, R.; MACEDO, V. L. Alfabetização: Lecto-escrita x bagagem cultural. Cadernos FAPA, Porto Alegre, Número Especial, p. 97, 2008. Disponivel:<www4.fapa.com.br"cadernosfapa"artigos"4edição.SP"artigo11.pdf>. Acesso em: 8 fev. 2009.

GOLDSTEIN, S.; GOLDSTEIN, M. Hiperatividade: como desenvolver a capacidade de atenção da criança. 11. ed. São Paulo: Papirus. 2006.

IZQUIERDO, I. Memória. Porto Alegre: Artmed, 2002.

KOLB, B.; WHISHAW, I. O. Fundamental of human neuropsychology. 4. ed. New York: W.H. Freeman and Company, 1996.

MALUF, M. I. Diagnóstico e intervenção psicopedagógica nos transtornos de aprendizagem. In: VALLE, L. E. L. R. et al. (Org.). Mente e corpo: integração multidisciplinar em neuropsicologia. Rio de Janeiro: Wasak, 2007.

MAUÉS, J. Inclusão e diversidade: notas indicativas para políticas públicas educacionais. In: PARÁ. Secretaria Executiva de Estado de Educação. A educação básica no Pará: elementos para uma política educacional democrática e de qualidade Pará Todos. Belém, 2008. v. 1.

MOTTER, B. C. Focal attention produces spatially selective processing in visual cortical areas $\mathrm{V} 1, \mathrm{~V} 2$ and $\mathrm{V} 4$ in presence of competing stimuli. Journal of Neurophysiology, Bethesda, MD, v. 70, p. 909-919, 1993.

PAPALIA, D. E.; OLDS, S. W. Desenvolvimento humano. 7. ed. Porto Alegre: Artmed, 2000.

PARÁ. Lei ñ. 7.077, de 28 de dezembro de 2007: Dispõe sobre o plano plurianual - PPA - para o período 2008-2011. Leis, Belém, PA, 28 dez. 2007. Disponível em: <http://www.sepof.pa.gov.br/ppa/leis_ppa.pdf>. Acesso em: 25 fev. 2010.

Secretaria Executiva de Estado de Educação. Política de educação básica do Estado do Pará. Belém, PA: SEDUC, 2008. v. 3.

RABELLO, R. A aplicação de estratégias metacognitivas. disciplina de bases neurais da motricidade humana. Rio de Janeiro: UCB, 2007. Apostila. 
RAZERA, G. Hiperatividade eficaz. Rio de Janeiro: Instituto Internacional de Projeciologia e Conscienciologia, 2001.

RELVAS, M. P. Neurociência e transtornos de aprendizagem. Rio de Janeiro: WAK, 2007.

SABOYA, E. et al. Disfunção executiva como uma medida de funcionalidade em adultos com TDAH. Jornal Brasileiro de Psiquiatria, Rio de Janeiro, v. 56, 2007. Suplemento 1.

SCHMIDT, R. A.; WRISBERG, C. A. Aprendizagem e performance motora: uma abordagem da aprendizagem baseada no problema. 2. ed. Porto Alegre: Artmed, 2001.

SIEVER, D. The rediscovery of áudio-visual entrainment technology. 5. ed. Alberta, Canada: Comptronic Devices Limited, 1999.

SILVA, M. F. M. C.; KLEINHANS, A. C. S. Processos cognitivos e plasticidade cerebral na Síndrome de Down. Revista Brasileira de Educação Especial, Marilia, SP, v. 12, n. 1. p. 123-138, jan./abr. 2006. Disponivel em:

<www.scielo.br/pdf/rbee/v12n1/31988.pdf >. Acesso em: 2 out. 2008.

SILVA, V. Metacognição: conteúdo de um segundo cérebro?: Laboratório de neuromotricidade: Rio de Janaeiro: UCB/RJ, 2004.

STEIN, L. M. TDE: teste de desempenho escolar: manual para aplicação e interpretação. São Paulo: Casa do Psicólogo, 1994.

THOMPSON, R. A prática do relaxamento visando a uma maior consciência corporal e ao aumento da capacidade atentiva em crianças com TDAH. In: VALLE, L. E. L. R. et al. (Org.). Mente e corpo: integração multidisciplinar em neuropsicologia. Rio de Janeiro: Wasak, 2007.

TOPCZWSKI, A. Hiperatividade, como lidar?. São Paulo: Casa do Psicólogo, 1999.

Recebido em: 26/11/2009

Aceito para publicação em: 14/12/2009 